\title{
Effect of Er: YAG laser etching on shear bond strength of orthodontic bracket
}

Radwa A. Sallam, MSc, PhD, Eman A. Arnout, MDS, PhD.

$$
\begin{aligned}
& \text { ABSTRACT } \\
& \text { الأهداف : لتقييم قوه القص الترابطيه لحفر الأسنان باستخدام الاربيم }
\end{aligned}
$$

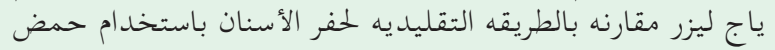

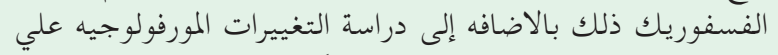

$$
\begin{aligned}
& \text { سطح مينا الأسنان باستخد الاضه المجهر الإِكتروني الناسخ. }
\end{aligned}
$$

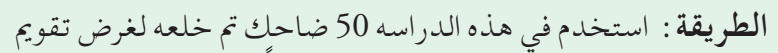

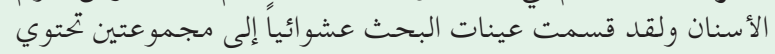

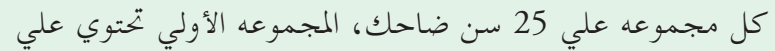

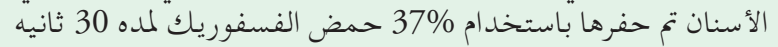

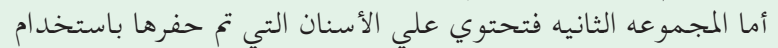

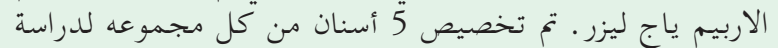

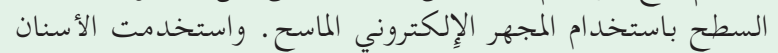

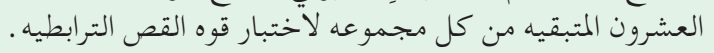

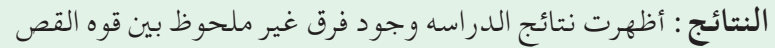

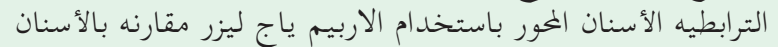

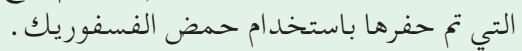

$$
\begin{aligned}
& \text { الحخاتمة: وبناء علي نتائج هذه الدراسة تم التوصل إلي أنه يمكن }
\end{aligned}
$$

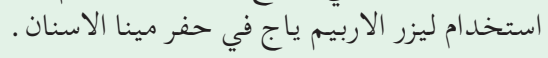

Objectives: To evaluate and compare the shear bond strength (SBS) of Erbium laser etched enamel to acid etched and to detect morphological changes on laser etched enamel surface using scanning electron microscope (SEM). Moreover, Laser induced caries resistance is advantageous in Orthodontics.

Methods: This is an Ex vivo study between January 2016 and December 2017, which comprises a total of 50 human premolars, extracted for orthodontic purpose, were used in this study. The samples were randomly divided into 2 groups of 25 each. The first group was etched using $37 \%$ phosphoric for 30 seconds. As for the second group, enamel was treated by Er: YAG laser operating at wavelength $2.94 \mu \mathrm{m}$, power $1.5 \mathrm{~W}$ and repetition rate $15 \mathrm{~Hz}$. Five teeth from each group were selected for SEM evaluation and the study were continued on 20 teeth from each group. Teeth were subjected to shear bond strength test.

Results: It showed, no-significant difference between the mean of shear bond strength and of the etched groups $(p=0.016)$.

Conclusion: It was concluded that, laser etched group $(1.5 \mathrm{~W} / 15 \mathrm{~Hz})$ resulted in clinically accepted bond strength and could be an alternative to conventional acid etching.

Saudi Med J 2018; Vol. 39 (9): 922-927

doi: $10.15537 /$ smj.2018.9.22793

From the Department of Health Radiation Research (Sallam), National Center for Radiation Research and Technology, Atomic Energy Authority, and from the Department of Oral Medicine (Arnout), Periodontology, Diagnosis and Oral Radiology, Faculty of Dentistry, Ain Shams University, Cairo, Egypt.

Received 24th April 2018. Accepted 19th July 2018.

Address correspondence and reprint request to: Dr. Eman A. Arnout, Department of Oral Medicine, Periodontology, Diagnosis and Oral Radiology, Faculty of Dentistry, Ain Shams University, Cairo, Egypt. E-mail:emanarnooo@gmail.com

ORCID ID: orcid.org/0000-0001-9624-9529

$\mathrm{T}$ The bonding of orthodontic brackets is mainly based on the mechanical interlocking of an adhesive to irregularities in the enamel surface created by previous enamel etching. Acid etching has been the conventional method of enamel conditioning since its development in $1955 .^{1-3}$ Enamel acid etching improves retention by hydroxyapatite eroding and subsequently facilitates penetration, via the production of resin tags. ${ }^{4}$ However, it can result in unintentional demineralization of the most superficial layer of the enamel surface, initiate caries around the metal bracket, expose the acid to uninvolved enamel, and prolong clinical manipulation., ${ }^{2,5}$

Throughout the past years, many studies have focused on finding alternative methods to conventional acid etching that are less damaging to the tooth structure and simultaneously yield optimum bond strength..$^{6-9}$ 
Lately, attention has been driven to the use of laser etching. It has attracted significant attention because it can remove the smear layer and results in an irregular surface pattern which is comparable to that of an acid etching pattern. ${ }^{10,11}$

It modifies the chemical and crystalline structure of the enamel and prevents caries. In addition, it is a painless procedure, it does not involve heat or vibration, and can be used without anesthesia. Moreover, it reduces chair time in the dental office. ${ }^{2,7,8,12}$ Since 1964 , several types of lasers have been introduced for use in dentistry; for example, ruby, neodymium-doped yttrium aluminum garnet (Nd: YAG), carbon dioxide, and erbium lasers. ${ }^{13}$ Compared to the other lasers, the Erbium laser is the most effective for hard tissue ablation with minimal thermal effects on the pulp. ${ }^{7,14,15}$

However, previous conducted studies comparing enamel etching with acid to that of laser were controversial. ${ }^{16}$ This posed a question whether Erbium laser etching could be an alternative to that of acid. Furthermore, different laser irradiation setting or different operation mode were used. ${ }^{11,17-20}$

According to our knowledge, no standard irradiation settings of enamel etching using Erbium Laser have been reached. Consequently, another question regarding the optimum parameters that could achieve optimum bod strength and be comparable to acid etching was raised.

In view of the questions raised, the purpose of the present study was designed with different parameters to evaluate and compare the SBS of Erbium laser etched enamel to acid etched. Moreover, to detect morphological changes on laser etched enamel surface using SEM.

Methods. Selection criteria and preparation. This is an Ex vivo study between January 2016 and December 2017, 50 sounds extracted human premolar teeth for orthodontic purposes and collected from discarded teeth after surgical extraction were used in this study. The 4 tooth selection criteria were: intact uncracked buccal enamel surface, restoration material, and caries. Teeth were cleaned thoroughly using tap water, brushed and scaled from any calculus, and then sterilized using a cobalt-60 gamma source (GB50 Type B, Canada) at a dose of $25 \mathrm{KGy}$ for 6 hours at room temperature. The samples were stored in saline solution until ready

Disclosure. Authors have no conflict of interests, and the work was not supported or funded by any drug company. for use. The buccal surface of the teeth was polished using a mixture of fluoride-free pumice powder and distilled water, with a rubber-polishing cup and low-speed hand piece for 15 seconds. Subsequently, all polished teeth were rinsed with water and dried with oil-free compressed air. To delineate the area for enamel conditioning, a piece of scotch tape with a pre-punched circular window of diameter $4 \mathrm{~mm}$ was adhered to the enamel surface of each tooth.

Enamel surface etching. The samples were allocated on random basis into 2 groups: (Group 1) The acid-etched group (control), which consisted of 25 premolar teeth which were etched using a $37 \%$ phosphoric acid gel (ExciTE F, Ivoclar Vivadent AG, FL-9494 Schaan/Liechtenstein) for 30 seconds, rinsed thoroughly with water, and dried in oil-free air until the enamel surface exhibited a frosty chalky appearance. (Group 2) The Laser-etched group, which consisted of 25 premolar teeth which were etched using Erbiumdoped yttrium aluminum garnet (Er: YAG, Fotona, Light walker AT, Ljubljana, Slovenia, EU). The laser device was operated at wavelength of $2940 \mathrm{~nm}$ at $1.5 \mathrm{~W}$, with an energy output of $100 \mathrm{~mJ}$, pulse duration of $140 \mu \mathrm{m}$, frequency of $15 \mathrm{~Hz}$, and a water flow rate of $48 \mathrm{~mL} / \mathrm{min}$. The beam was directed perpendicular to the enamel at a distance of $3 \mathrm{~mm}$ from the tooth surface to the laser tip and moved in an extensive fashion for 20 seconds under water spray. Then, an oil-free air was used to dry the tooth surface until the enamel surface exhibited a frosty chalky appearance.

Scanning electron microscopy analysis. Five teeth from each group were randomly selected to examine morphological changes on the enamel surface via SEM, while the other 20 teeth from each group underwent bracket bonding (JEOL JSM 5400, Tokyo, Japan).

Bonding techniques. Forty self-cured acrylic blocks ( $\mathrm{n}=20$ for each group) were made to mount teeth that would be subjected to the SBS test. Blocks were color-coded to differentiate between the 2 groups. A stainless-steel premolar bracket (Gemini series Roth, 3M Unitek, Monrovia, CA, USA) with a 0.022 in slot and a base area of $9.806 \mathrm{~mm}^{2}$, as per manufacturer's specifications, were used in this study. The brackets were bonded to the anatomical crowns using a thin layer of no-mix composite (Transbond TM XT Light cure adhesive, 3M Unitek, Monrovia, CA, USA). After removing excess adhesive with a probe, the brackets were light-cured for 40 seconds.

Shear bond strength evaluation. The SBS of the samples was measured using an Instron universal testing machine (Hampshire Ltd, Bognor Regis, England). 
Table 1 - Data explored for normality using Kolmogorov-Smirnov tests.

\begin{tabular}{|c|c|c|c|c|c|c|c|}
\hline \multirow[t]{2}{*}{ Statistical tests } & & \multicolumn{3}{|c|}{ Acid etched group 1} & \multicolumn{3}{|c|}{ Laser etched group 2} \\
\hline & & Statistic & Std. Error & Bias & Statistic & Std. Error & Bias \\
\hline Mean & & 8.988 & .4049 & -.006 & 9.600 & .2610 & .001 \\
\hline \multirow{2}{*}{$\begin{array}{l}95 \% \text { Confidence } \\
\text { Interval for Mean }\end{array}$} & Lower Bound & 8.125 & & & 9.049 & & \\
\hline & Upper Bound & 9.850 & & & 10.151 & & \\
\hline $5 \%$ Trimmed Mean & & 8.997 & & -.008 & 9.539 & & .011 \\
\hline Median & & 9.250 & & -.122 & 9.200 & & .171 \\
\hline Variance & & 2.623 & & -.153 & 1.226 & & -.070 \\
\hline Std. Deviation & & 1.6194 & & -.0560 & 1.1072 & & -.0515 \\
\hline Minimum & & 6.8 & & & 8.3 & & \\
\hline Maximum & & 11.0 & & & 12.0 & & \\
\hline Range & & 4.2 & & & 3.7 & & \\
\hline Interquartile Range & & 3.4 & & -.4 & 1.4 & & .1 \\
\hline Skewness & & -.100 & .564 & -.008 & 1.052 & .536 & -.147 \\
\hline Kurtosis & & -1.702 & 1.091 & .337 & .647 & 1.038 & -.118 \\
\hline
\end{tabular}

Table 2 - Statistical tests indicated no statistically significant difference between the acid-etched and laser-etched groups.

\begin{tabular}{lccccccc}
\hline Etching techniques & & \multicolumn{5}{c}{ Statistical tests } & $P$-value \\
& & Statistic & Bias & Std. Error & $95 \%$ Confidence Interval & \\
& & & & & Lower & Upper & \\
\hline \multirow{3}{*}{ Acid etched group 1 } & Mean & 8.988 & .013 & .404 & 8.153 & 9.776 & \\
& Std. Deviation & 1.6194 & -.0611 & .1558 & 1.2147 & 1.8212 & \\
& Std. Error Mean & .4049 & & & & & \multirow{2}{*}{0.016} \\
& Mean & 9.600 & .007 & .260 & 9.141 & 10.138 & \\
Laser etched group 2 2 Std. Deviation & 1.1072 & -.0435 & .1981 & .6371 & 1.4191 & \\
& Std. Error Mean & .2610 & & & & & \\
\hline
\end{tabular}

The machine blade was inserted between the resin and ortho-bracket and then a vertical occluso-gingival force was applied at a cross head speed of $1 \mathrm{~mm} / \mathrm{min}$. The measured bond strength was directly recorded in Newtons, and then converted into mega Pascal ( $\mathrm{MPa})$ units.

Statistical analysis. Data are presented as mean and standard deviation (SD). The data were analyzed for normality using Kolmogorov-Smirnov tests. An independent t-test was used to compare between the etching techniques. A $p$-value $\leq 0.05$ was considered significant. Statistical analysis was carried out using IBM $^{\circledast}$ SPSS $^{\circledast}$ Version 25 (IBM Corp., Armonk, NY, USA).

Ethical consideration. The Medical Research Ethics Committee of National Centre of Atomic Research and Technology approved our study; as all subjects were unknown a waiver of informed consent was accepted.

Results. Numerical data was explored for normality using Kolmogorov-Smirnov tests as shown in (Table 1). In addition to check the distribution curves.
Shear bond strength. Shear bond strength showed normal parametric distribution. Analysis of variance using student's t-test was used to compare between the 2 groups. A significant level was set at $p \leq 0.05$. Our results indicated no statistically significant difference $(p=0.016)$ between the acid-etched $(8.988 \pm 1.6194)$ and laser-etched (9.600 \pm 1.1072$)$, (Table 2) groups.

Scanning electron microscope of enamel surface. Scaning electron microscope was performed after acid etching using $37 \%$ phosphoric acid for 30 seconds, the resulting samples showed enamel surface roughness and preferential dissolution of the prism cores, resulting in a honeycomb-like appearance. (Figures $1 \& 2$ ).

Enamel surface after Er: YAG laser irradiation. Specimens conditioned with a Er: YAG laser exhibited areas of ablated enamel surface, with a combination of preferential dissolution of prism cores and prism peripheries, areas of hollowed prism cores adjacent to areas of demineralized prism peripheries, and crater formation (Figures $3 \& 4$ ). 


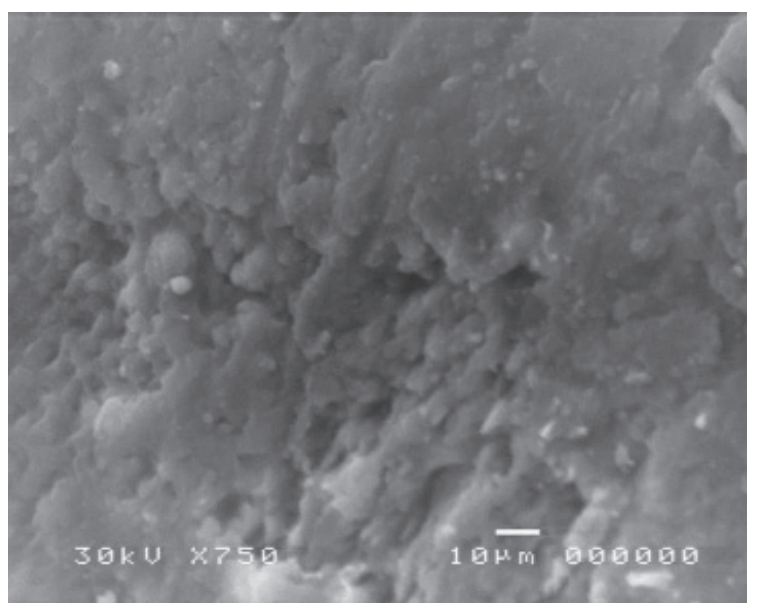

Figure 1 - Enamel surface roughness after conventional acid etching for 30 seconds $(\times 750)$.

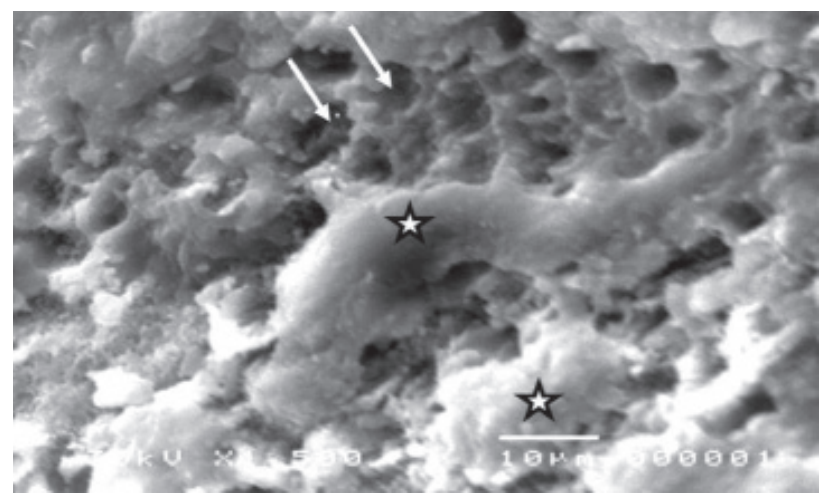

Figure 2 - Enamel surface after conventional acid etching for 30 seconds $(\times 1500)$. The enamel surface has the appearance of a characteristic regular honey comb (arrow), with areas of aprismatic enamel (star)

Discussion. The Erbium laser is one of the most widely used lasers for hard tissue ablation. Erbium lasers emit a wavelength of $2.94 \mu \mathrm{m}$ which matches -OH groups in hydroxyapatite $2.8 \mu \mathrm{m}$ and the main absorption band of water $(3 \mathrm{~mm}) .{ }^{21}$ Thus, the irradiation is absorbed strongly by water and increases its affinity for hydroxyl apatite with minimal thermal effect on the pulp. ${ }^{1,3,16}$ In this study, Erbium laser etching was compared to acid etching using $37 \%$ phosphoric acid as a control group, since it is the standard and most common etching method. Moreover, to preserve enamel integrity without decreasing bond strength, the etching time was set to 30 seconds, as suggested in several previous studies. ${ }^{22,23}$

Various studies have been performed to investigate laser etching using different irradiation settings. The

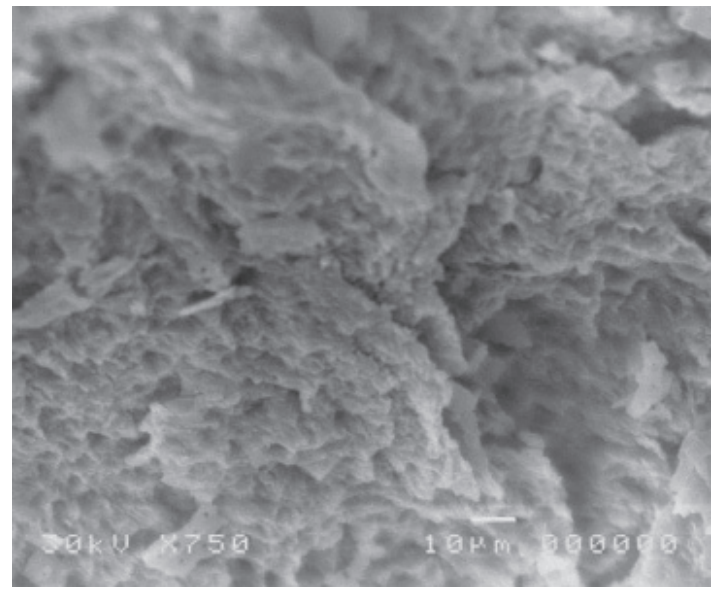

Figure 3 - Enamel surface after Er:YAG laser irradiation $(\times 750)$ showing surface roughness and crater formation (arrow).

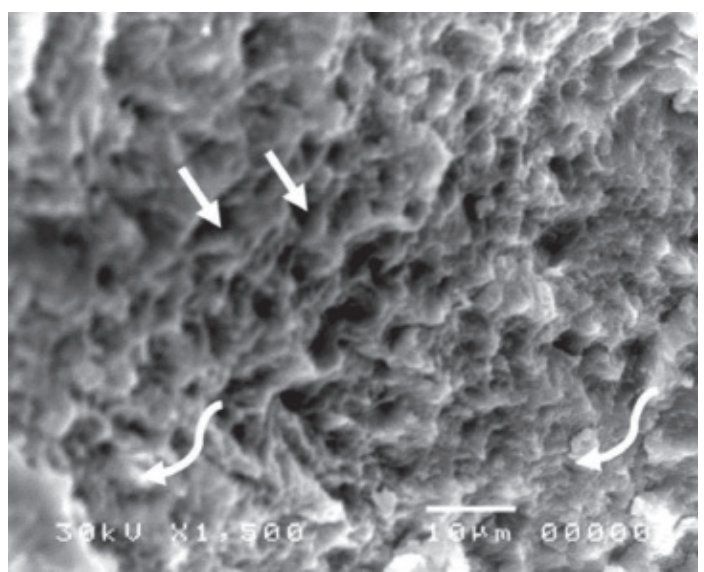

Figure 4 - Enamel surface roughness after Er: YAG laser irradiation $(\times 1500)$. Resorption of the prism cores was observed when the peripheral boundaries were highly projected (arrows).

parameters used in this study were chosen so that the energy output would not exceed $100 \mathrm{~mJ}$ (power 1.5W, pulse repetition rate $15 \mathrm{~Hz}$ ), so as not to destroy the enamel. ${ }^{24}$ Samples were irradiated using a short pulse duration $(140 \mu \mathrm{m})$ to effectively modify the enamel surfaces with low thermal impact on the pulp. ${ }^{16}$ Moreover, an external water supply was used for safe and efficient ablation of the enamel. ${ }^{25}$

Scanning electron microscope imaging and SBS tests were conducted to evaluate the changes to the enamel after etching. Scanning electron microscope of the acid-etched group (group 1/control) resulted in a honey comb type I etching pattern. ${ }^{8}$

Interestingly, areas of non-etched enamel were observed despite the adequate SBS of the acid-etched group (8.988 MPa). This is likely because an ideal acid 
etching pattern is not necessarily correlated with or influences bond strength. ${ }^{8}$

On the other hand, SEM images of the laser-etched group (group 2) showed profound surface roughness with a type III Silverstone etching pattern (Figures $4 \& 5$ ). This finding was in agreement with several previous studies. ${ }^{20,21}$ The laser-etched group exhibited clinically acceptable SBSs of $13.59 \mathrm{MPa}$.

The comparison of SBS of the acid-etched and laser-etched groups revealed no statistically significant difference between SBSs. This is in agreement with previous studies which used the same radiation power (1.5W) and concluded that adequate etching of orthodontic bonding is achieved when irradiation with a $1.5 \mathrm{~W}$ laser used. ${ }^{26,27}$

Similarly, it was concluded that low-power Er: YAG laser etching results in clinically acceptable SBS values. ${ }^{20}$ In addition, our results were in accordance with other literature that used different brackets materials. ${ }^{28,29}$

Furthermore, laser etching at $100 \mathrm{~mJ}$ energy (the energy output used in this study) was found to be adequate for bond strength, and Er: YAG laser etching provides a viable alternate to regular acid-etching. ${ }^{1}$

Conversely, the results presented herein conflict with 2 previous studies that showed a significant difference in SBS between acid-etched and Er: YAG laser-etched groups. ${ }^{3,11}$

This conflict may be due to the different samples used (human/bovine teeth), different laser machines, different laser irradiation settings (power output, pulse repetition rate, pulse duration settings, energy output, and irradiation time), or different operation modes (contact or non-contact mode, external water cooling, and irradiation distance). Further studies are required to determine standard and optimal parameters for laser etching. Being an Ex-vivo study, as an In-vivo study is inapplicable because of ethical consideration.

In conclusion, Erbium laser etching imparts clinically acceptable shear bond strength of $13.59 \mathrm{MPa}$. There was no statistically significant difference between the shear bond strength of the laser-etched and acid-etched groups and there is no significant relationship between the bond strength and etching pattern.

\section{References}

1. Alavi S, Birang R, Hajizadeh F. Shear bond strength of orthodontic brackets after acid-etched and erbium-doped yttrium aluminum garnet laser-etched. Dent Res J (Isfahan) 2014; 11: 321-326.

2. Ghaffari H, Mirhashemi A, Baherimoghadam T, Azmi A, Rasooli R. Effect of Surface Treatment on Enamel Cracks After Orthodontic Bracket Debonding: Er,Cr:YSGG Laser-Etching Versus Acid-Etching. J Dent (Tehran) 2017; 14: 259-266.
3. Sfondrini MF, Calderoni G, Vitale MC, Gandini P, Scribante A. Is laser conditioning a valid alternative to conventional etching for aesthetic brackets? Eur J Paediatr Dent 2018; 19 : 61-66.

4. Giannini M, Makishi P, Ayres AP, Vermelho PM, Fronza BM, Nikaido T, et al. Self-etch adhesive systems: a literature review. Braz Dent J 2015; 26: 3-10.

5. Kang Y, Rabie AB, Wong RW. A review of laser applications in orthodontics. Int J Orthod Milwaukee 2014; 25: 47-56.

6. de Jesus Tavarez RR, Lima Bezerra G, de Souza Penha KJ, Torres CR, Firoozmand LM. Er:YAG pre-treatment for bonding of orthodontic bracket: 1 year of in vitro treatment. Clin Cosmet Investig Dent 2017; 9: 19-25.

7. Hoshing UA, Patil S, Medha A, Bandekar SD. Comparison of shear bond strength of composite resin to enamel surface with laser etching versus acid etching: An in vitro evaluation. $J$ Conserv Dent 2014; 17: 320-324.

8. Akhoundi MSA, Etemadi A, Nasiri M, Borujeni ES. Comparison of Enamel Morphologic Characteristics after Conditioning with Various Combinations of Acid Etchant and Er:YAG Laser in Bonding and Rebonding Procedures: A SEM Analysis. J Dent (Tehran) 2017; 14: 144-152.

9. Heravi F, Shafaee H, Abdollahi M, Rashed R. How Is the Enamel Affected by Different Orthodontic Bonding Agents and Polishing Techniques? J Dent (Tehran) 2015; 12: 188-194.

10. Shafiei F, Jowkar Z, Fekrazad R, Khalafi-Nezhad A. Micromorphology analysis and bond strength of two adhesives to Er,Cr:YSGG laser-prepared vs. bur-prepared fluorosed enamel. Microsc Res Tech 2014; 77: 779-784.

11. Contreras-Bulnes R, Scougall-Vilchis RJ, Rodríguez-Vilchis LE, Centeno-Pedraza C, Olea-Mejía OF, Alcántara-Galena Mdel C. Evaluation of self-etching adhesive and Er:YAG laser conditioning on the shear bond strength of orthodontic brackets. Scientific WorldJournal 2013; 2013: 719182.

12. Krishnan K, Kumaran NK, Iyer VH, Rajasigamani K. Laser etched vs conventional etched enamel: Effect on shear bond strength of orthodontic brackets. Int J Laser Dent 2013; 3: $1-6$.

13. Karandish M. The efficiency of laser application on the enamel surface: a systematic review. J Lasers Med Sci 2014; 5: 108-114.

14. Nalcaci R, Cokakoglu S. Lasers in orthodontics. Eur J Dent 2013; 7: S119-S125.

15. Seifi M, Matini NS. Laser Surgery of Soft Tissue in Orthodontics: Review of the Clinical Trials. J Lasers Med Sci 2017; 8: S1-S6.

16. Sağır S, Usumez A, Ademci E, Usumez S. Effect of enamel laser irradiation at different pulse settings on shear bond strength of orthodontic brackets. Angle Orthod 2013; 83: 973-980.

17. Sawan M, Hussain N, Alkurdi M. Etching of enamel by laser energy for direct bonding of orthodontic appliance and evaluation of shear bond strength. Energy Procedia 2015; 74 : 1452-1458.

18. Aglarci C, Demir N, Aksakalli S, Dilber E, Sozer OA, Kilic HS. Bond strengths of brackets bonded to enamel surfaces conditioned with femtosecond and Er:YAG laser systems. Lasers Med Sci 2016; 31: 1177-1183.

19. Fornaini C, Brulat N, Milia G, Rockl A, Rocca JP. The use of sub-ablative Er:YAG laser irradiation in prevention of dental caries during orthodontic treatment. Laser Ther 2014 30; 23: 173-181. 
20. Yassaei S, Fekrazad R, Shahraki N, Goldani Moghadam M. A Comparison of Shear Bond Strengths of Metal and Ceramic Brackets using Conventional Acid Etching Technique and Er:YAG Laser Etching. J Dent Res Dent Clin Dent Prospects 2014; 8: 27-34.

21. Ierardo G, Di Carlo G, Petrillo F, Luzzi V, Vozza I, Migliau G, et al. Er:YAG laser for brackets bonding: a SEM study after debonding. Scientific WorldJournal 2014; 2014: 935946.

22. Ravindranath MJ, Mahendra L, Rajasigamani K, Kumaran K. Comparison of Morphological Variation and Shear Bond Strength Between Conventional Acid Etchant at Different Etch Times and Self Etching Primer-An in Vitro Study. International Journal of Pharma Medicine and Biological Sciences. 2015; 1(20): 9-4035.

23. Ioannidis A, Papageorgiou SN, Sifakakis I, Zinelis S, Eliades $\mathrm{G}$, Eliades T. Orthodontic bonding and debonding induces structural changes but does not alter the mechanical properties of enamel. Prog Orthod 2018; 19: 12.

24. Dostálová T, Jelínková H, Krejsa O, Hamal K, Kubelka J, Procházka S. Er: YAG Laser etching of enamel. Scanning Microscopy 1998; 12: 2.
25. Topcuoglu T, Oksayan R, Ademci KE, Goymen M, Usumez S, Usumez A. Effects of water flow rate on shear bond strength of orthodontic bracket bonded to enamel surface after Er:YAG laser ablation. Photomed Laser Surg 2013; 31: 486-491.

26. Jamenis SC, Kalia A, Sharif K. Comparative Evaluation of Shear Bond Strength of Orthodontic Brackets using Laser Etching and Two Conventional Etching Techniques: An in vitro Study. Journal of Indian Orthodontic Society 2011; 45: 134-139.

27. Ozer T, Başaran G, Berk N. Laser etching of enamel for orthodontic bonding. Am J Orthod Dentofacial Orthop 2008; 134: 193-197.

28. Mirhashemi AH, Chiniforush N, Sharifi N, Hosseini AM. Comparative efficacy of Er,Cr:YSGG and Er:YAG lasers for etching of composite for orthodontic bracket bonding. Lasers Med Sci 2018; 33: 835-841.

29. Nalcaci R, Temel B, Çokakoğlu S, Türkkahraman H, Üsümez S. Effects of laser etching on shear bond strengths of brackets bonded to fluorosed enamel. Niger J Clin Pract 2017; 20: 545-551. 